\title{
The therapeutic effect to eldecalcitol + bisphosphonate is superior to bisphosphonate alone in the treatment of osteoporosis: a meta-analysis
}

Zaoqian Zheng ${ }^{1,2,3}$ and Jinyu Luo ${ }^{4^{*}}$

\begin{abstract}
Background: Osteoporosis is a metabolic bone disease. Bisphosphonate (BP) and eldecalcitol (ELD) are two clinical first-line drugs for osteoporosis patients. However, the effect of ELD + BP vs. BP alone on osteoporosis treatment is still unclear. The present meta-analysis was conducted to evaluate the different therapeutic effect of BP + ELD vs. $\mathrm{BP}$ alone in osteoporosis treatment.

Methods: Eligible documents that selected from online databases including PubMed, Embase, and Cochrane Library were included in this study (updated to March 3, 2020). The quality assessment of the included studies was based on the guidelines of Cochrane. Meta-analysis was performed according to criteria such as intervention plan and outcome. The indicators including bone mineral density (BMD) in all enrolled studies were included in the current analysis. Pooled odds ratios (ORs) and weighted mean differences (WMDs) with 95\% confidence intervals (Cl) were calculated using fixed- or random-effects models. Then, heterogeneity analysis was performed based on Cochran's $Q$ test and $P^{2}$ statistics.

Results: A total of 4 studies (456 cases) with high quality were enrolled in this study. The effect of ELD + BP was superior to BP alone based on indicators including femoral neck BMD (FN-BMD) and total hip BMD (TH-BMD) in patients with followed up $\leq 6$ months. Moreover, the effect of ELD + BP was superior to BP alone based on lumbar spine BMD (LS-BMD) in patients with 12 months followed up.
\end{abstract}

Conclusion: Therapeutic effect of ELD + BP was superior to BP alone in osteoporotic patients based on the influence of BMD.

Keywords: Osteoporosis, Bisphosphonate, Eldecalcitol, Therapeutic effect, Bone mineral density, Meta-analysis

\footnotetext{
*Correspondence: ljy173481370@163.com

${ }^{4}$ Hemopurification Center, Division of Nursing, Tongde Hospital of Zhejiang

Province, No. 234 Gucui Road, Xihu District, Hangzhou 310012, Zhejiang

Province, China

Full list of author information is available at the end of the article
}

C C The Author(s). 2020 Open Access This article is licensed under a Creative Commons Attribution 4.0 International License, which permits use, sharing, adaptation, distribution and reproduction in any medium or format, as long as you give appropriate credit to the original author(s) and the source, provide a link to the Creative Commons licence, and indicate if changes were made. The images or other third party material in this article are included in the article's Creative Commons licence, unless indicated otherwise in a credit line to the material. If material is not included in the article's Creative Commons licence and your intended use is not permitted by statutory regulation or exceeds the permitted use, you will need to obtain permission directly from the copyright holder. To view a copy of this licence, visit http://creativecommons.org/licenses/by/4.0/ The Creative Commons Public Domain Dedication waiver (http://creativecommons.org/publicdomain/zero/1.0/) applies to the data made available in this article, unless otherwise stated in a credit line to the data. 


\section{Background}

Osteoporosis is a group of bone diseases characterized by bone pain and easy fracture [1]. This disease lead to a total of 8.9 million fractures in 1 year all over the world [2]. Although the monitoring therapy based on bone mineral density (BMD) measurement contributes to the fracture diagnose, there is still a high mortality in people with osteoporosis due to the complications of fracture $[3,4]$. Thus, effective drug prevention and treatment is necessary for people with osteoporosis or suffering osteoporotic fracture [5].

Bisphosphonate (BP) is one of the most commonly used first-line drugs for the clinical therapy of osteoporosis [6]. It contributes to the decrease of future fracture occurrence in patients with osteoporosis via change in the expression of blood mRNA in the process of osteoporosis $[7,8]$. In Japan, a previous 2-year multicenter study shows that weekly used BP treatment significantly increases the quality of life osteoporosis patients [9]. On the contrary, some studies prove that BP not only is unsuitable for secondary osteoporosis treatment in children, but also do not appear to change the overall risk of death $[10,11]$. Furthermore, eldecalcitol (ELD) is an active analog of vitamin D commonly used for the clinical treatment of osteoporosis [12]. A clinical study shows that ELD can reduce the re-absorption of blood calcium into the bone, improve the absorption of calcium in the intestine, and then further increase the bone density in osteoporosis patients [13]. Compared with other drugs such as alfacalcidol, ELD is more effective in preventing vertebral and wrist fractures in osteoporotic patients [14]. Actually, ELD + BP is useful for the osteoporotic patients who undergo the long-time BP therapy [15]. Increase in BMD by BP + ELD-treated osteoporotic patients is associated with the serum calcium level within the reference interval [16]. However, some studies indicated that compared with the BP-associated combination therapy, the BP treatment alone significantly increased the therapy effect in osteoporotic patients [17-19]. The clinical advantages of BP alone in the treatment of osteonecrosis compared with combined therapy have also been confirmed by multi-center studies [20]. To sum up, although previous studies prove the effect of $\mathrm{BP}$ alone or $\mathrm{BP}$ + ELD in clinical treatment of osteoporosis patients, it is still not clear which treatment strategy is better due to the limited sample size in each study. Therefore, it is necessary to explore more comprehensively and objectively the therapeutic effect of BP alone and BP + ELD on osteoporosis patients based on a meta-analysis.

In this study, the related articles which meet the certain inclusion criteria in Embase, PubMed, and Cochrane Library databases were searched. The indicators including BMD, blood calcium, blood phosphorus, and TRACP-5b in all enrolled RCT and non-RCT studies were included in the current analysis. Meta-analysis was performed according to criteria such as different indicators and outcome. The current study was aimed to evaluate the therapeutic effect of BP + ELD vs. BP in osteoporosis treatment.

\section{Methods \\ Data sources}

Relevant studies were searched from electronic databases including Embase, PubMed, and Cochrane Library (updated to March 3, 2020). The main searching keywords included the following: ("Eldecalcitol" OR "Bisphosphonate") AND ("alendronate" OR "pamidronate" OR "ibandronate" OR "risedronate" OR "clodronate" OR "minodronate" OR "osteoporosis"). The detail information for search steps and corresponding results were shown in Table 1. Additionally, references of paper documents were hand searched for additional information on the procedures. No language restrictions were imposed in the current metaanalysis.

\section{Inclusion and exclusion criteria}

The inclusion criteria for articles were as follows: (i) the study subjects were patients with osteoporosis; (ii) the experimental group received ELD combined with BP treatment, and the control group was treated with $\mathrm{BP}$ alone (the types of BP (alendronate, ibandronate, risedronate, minodronate, etc.); (iii) the outcome of the study was based on indicators such as BMD (lumbar spine BMD (LS-BMD)), total hip BMD (TH-BMD), FNBMD, blood calcium, blood phosphorus, and TRACP$5 \mathrm{~b}$; and (iv) research type was clinical research including RCT, non-RCT, and other clinical studies. The beforeafter studies were excluded from the analysis. If more than one study were published by the same sample, then only one study (the latest study or the completest study) was extracted. Moreover, the non-treatise literatures including reviews, letters, and comments were excluded.

\section{Data extraction and quality assessment}

A total of 2 independent researchers participate in the data extraction in current meta-analysis. The strategies including discussion and reexamination were used for the problems during the article research. The available data including name of first author, year of publication, country, type of research, age, gender, sample size, and intervention plan, as well as outcome information in each literature, were enrolled in this study. Cochrane was used for the quality assessment [21]. A panel discussion with a third member was used to deal with disputes arising from current data retrieval process. 
Table 1 The detail information for search steps and corresponding results from PubMed (retrieval time: March 3, 2020)

\begin{tabular}{|c|c|c|}
\hline Search & Query & $\begin{array}{l}\text { Items } \\
\text { found }\end{array}$ \\
\hline$\# 1$ & "eldecalcitol"[Supplementary Concept] OR "eldecalcitol"[All Fields] & 177 \\
\hline$\# 2$ & $\begin{array}{l}\text { ("diphosphonates"[MeSH Terms] OR "diphosphonates"[All Fields] OR "bisphosphonate"[All Fields]) OR "diphosphonate"[All Fields]) OR } \\
\text { "bisphosphonates"[All Fields]) OR Bisphosphate[All Fields] OR ("alendronate"[MeSH Terms] OR "alendronate"[All Fields]) OR } \\
\text { ("pamidronate"[MeSH Terms] OR "pamidronate"[All Fields]) OR "zoledronic acid"[All Fields] OR ("ibandronic acid"[MeSH Terms] OR } \\
\text { ("ibandronic"[All Fields] AND "acid"[All Fields]) OR "ibandronic acid"[All Fields] OR "ibandronate"[All Fields]) OR ("risedronic acid"[MeSH } \\
\text { Terms] OR ("risedronic"[All Fields] AND "acid"[All Fields]) OR "risedronic acid"[All Fields] OR "risedronate"[All Fields]) OR ("clodronic } \\
\text { acid"[MeSH Terms] OR ("clodronic"[All Fields] AND "acid"[All Fields]) OR "clodronic acid"[All Fields] OR "clodronate"[All Fields]) OR ("YM } \\
\text { 529"[Supplementary Concept] OR "YM 529"[All Fields] OR "minodronate"[All Fields]) OR ("3-(2,2,2- } \\
\text { trimethylhydrazine)propionate"[Supplementary Concept] OR "3-(2,2,2-trimethylhydrazine)propionate"[All Fields] OR "mildronate"[All Fields]) }\end{array}$ & $\begin{array}{l}57, \\
670\end{array}$ \\
\hline$\# 3$ & $\begin{array}{l}\text { "osteoporosis, postmenopausal"[MeSH Terms] OR ("osteoporosis"[All Fields] AND "postmenopausal"[All Fields]) OR "postmenopausal } \\
\text { osteoporosis"[All Fields] OR "osteoporosis"[All Fields] OR "osteoporosis"[MeSH Terms] }\end{array}$ & $\begin{array}{l}87, \\
049\end{array}$ \\
\hline \#4 & \#1 AND \#2 AND 3 & 33 \\
\hline
\end{tabular}

\section{Statistical analysis}

The RevMan software (version: 5.3, Oxford, UK) was used for the statistical analysis in current study. Weighted mean difference (WMD) and 95\% confidence interval (CI) were used as the effect size for the evaluation of continuous variable. The mean difference (MD) and standard deviation (SD) of each evaluation index before and after the intervention in the ELD + BP group and BP group were used as the effect values for difference comparison. Then, the meta-analysis was used to assess whether there was a significant difference in MD between the two groups.

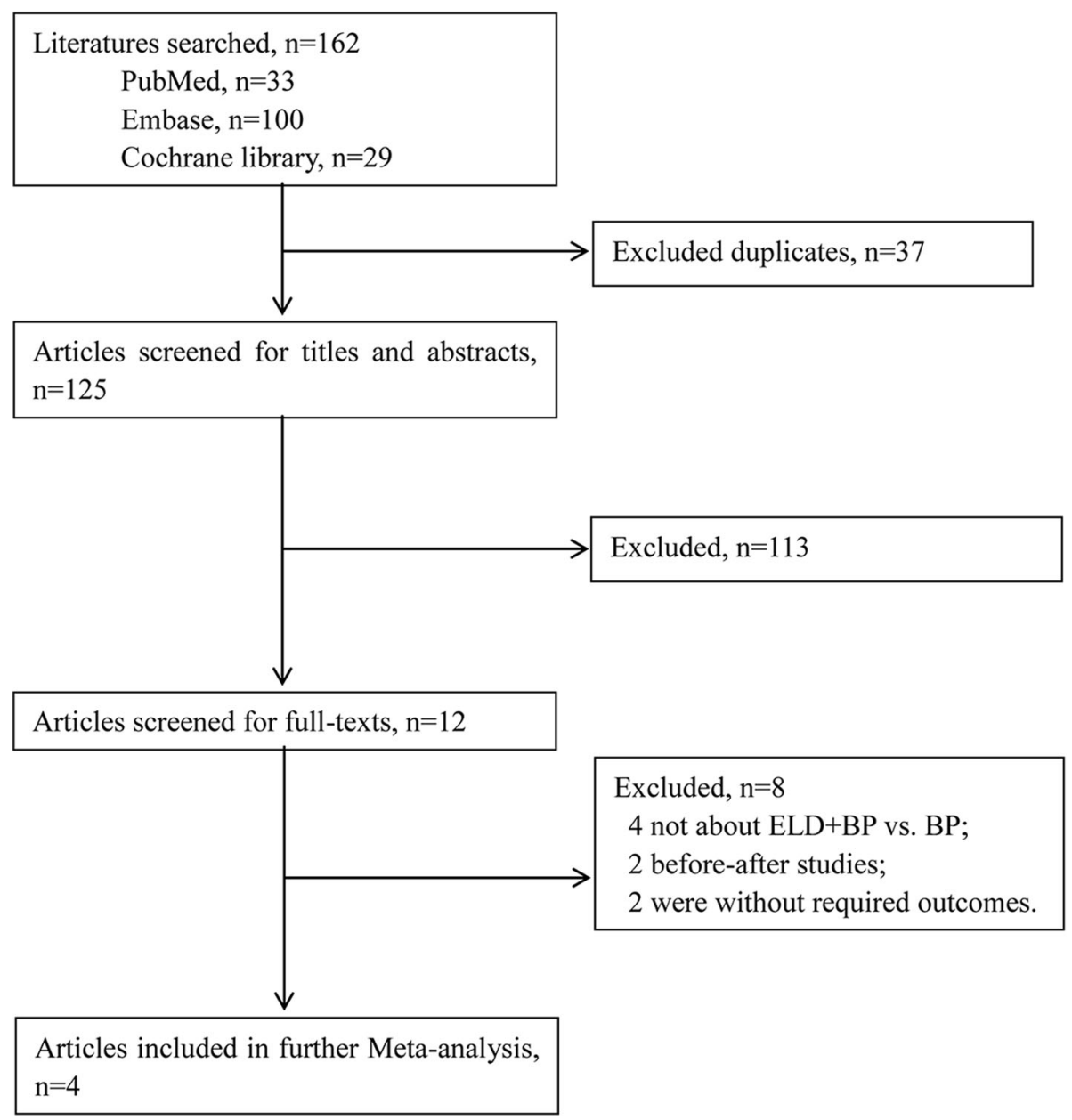

Fig. 1 Flow diagram of screening process for eligible articles 


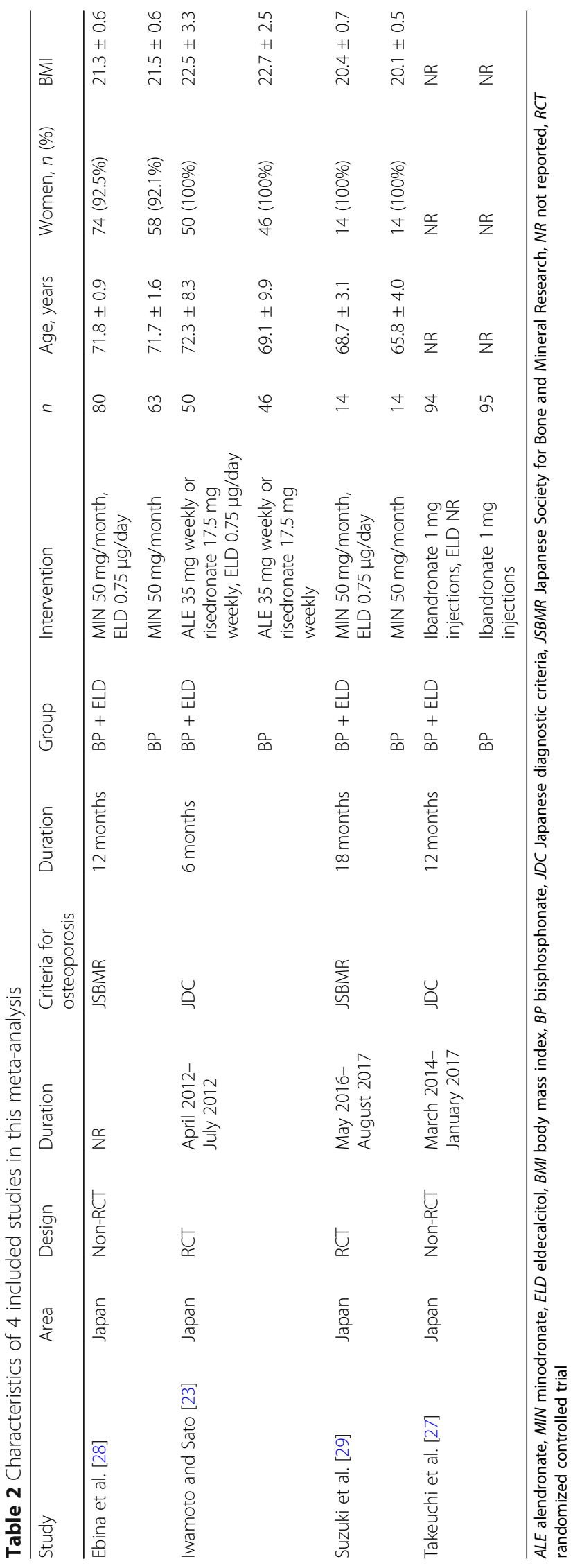


Then, heterogeneity analysis was performed based on Cochran's $Q$ test and $I^{2}$ statistics [22]. A random-effects model was used if heterogeneity was observed $(P<0.05$ or $\left.I^{2}>50 \%\right)$; otherwise, a fixed-effects model was applied. Furthermore, sensitivity analysis is used in the current research to analyze the impact of the combined outcomes after the literature was proposed one by one. Finally, the publication bias was evaluated by a funnel plot.

\section{Results}

\section{Included studies}

A total of 33, 100, and 29 studies in PubMed, Embase, and Cochrane library database, respectively, were included (Fig. 1). After deletion of the duplicate articles, a total of 125 studies were selected. After reading the title and abstract, a total of 113 articles were further excluded because these studies were not eligible for inclusion criteria. From the remaining 12 studies, 8 studies (4 studies without ELD + BP vs. BP; 2 before-after studies and 2 studies without required outcomes) were filtered out after reading the full text. Finally, totally, 4 studies with sufficient data including 2 RCT $[23,24]$ and 2 non-RCT $[25,26]$ were enrolled for the present meta-analysis (Table 2).

\section{Information for all enrolled literatures}

The publication year of the 4 literatures was from 2014 to 2019. The research areas mainly focused on Japan. A total of 456 cases were enrolled, including 238 in the ELD + BP group and 218 in the BP group. Except for the research by Takeuchi et al. [27], there was no significant difference in age and BMI between ELD + BP group and BP group in all studies. The intervention plan of Ebina et al. [28] was same with Suzuki et al. [29]. The follow-up period of each study was $6-18$ months. The results of literature quality evaluation showed that the risk of selection bias in the included studies was relatively high. All studies had not reported the implementation of a blind method on measurement of implementers, research objects, and outcomes. Therefore, the evaluations of "blinding of participants and personnel" and "blinding of outcomes assessment" were defined as "unclear risk" (Fig. 2). However, the other evaluation items were defined as "low risk." Overall, the methodological bias included in each literature was moderate (Fig. 3).

\section{Meta-analysis}

All events were divided according to the follow-up time ( $\leq 6$ months and 12 months) in the subsequent analysis due to the different follow-up times in each study. A total of 3 studies [27-29] reported the outcomes of LSBMD with follow-up time of less than 6 months. Since the heterogeneity test among these 3 studies [27-29] were statistically significant $\left(P=0.06, I^{2}=65 \%\right)$, the random-effect model was used. The difference of LSBMD between ELD + BP and BP (WMD (95\%CI) = $\left.0.0129(-0.0011,0.0269) \mathrm{g} / \mathrm{cm}^{2}, P=0.07\right)$ (Fig. 4a) was not significant. Moreover, there were 2 studies [28, 29] that reported the outcomes of FN-BMD and TH-BMD with follow-up time less than 6 months. Since the heterogeneity test among these 2 studies $[28,29]$ were not statistically significant $\left(P>0.05, I^{2}<50 \%\right)$, the fixedeffect model was used to calculate the WMD values and 95\% CI. The difference between ELD + BP and BP for both FN-BMD (WMD $(95 \% \mathrm{CI})=0.0085(0.0008$, $0.0162) \mathrm{g} / \mathrm{cm}^{2}$ ) (Fig. 4b) and TH-BMD (WMD (95\%CI) $\left.=0.0116(0.0049,0.0183) \mathrm{g} / \mathrm{cm}^{2}\right)$ (Fig. 4c) was significant, which further indicate the better effect of ELD + $\mathrm{BP}$ on increasing bone density. Furthermore, a total of 2 studies $[29,30]$ reported the outcomes of serum calcium

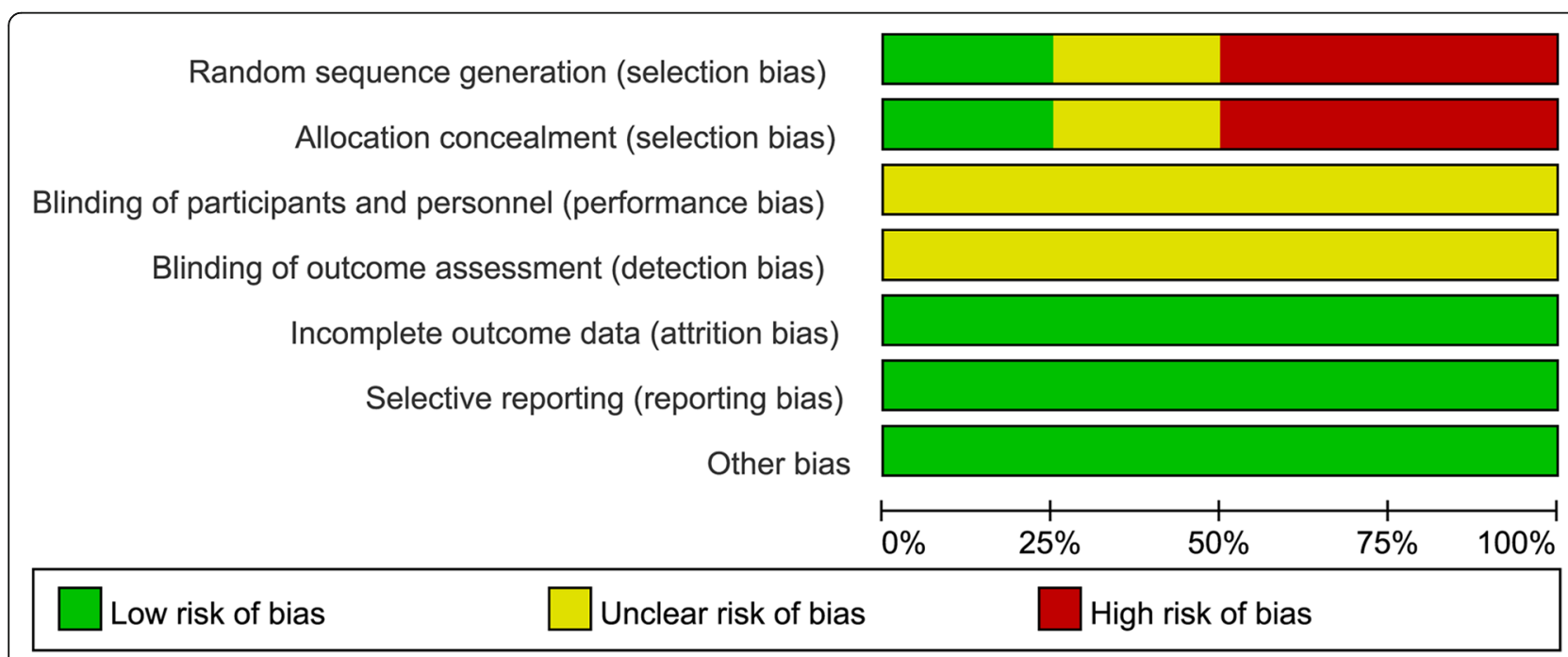

Fig. 2 The publication bias evaluation based on enrolled literatures 


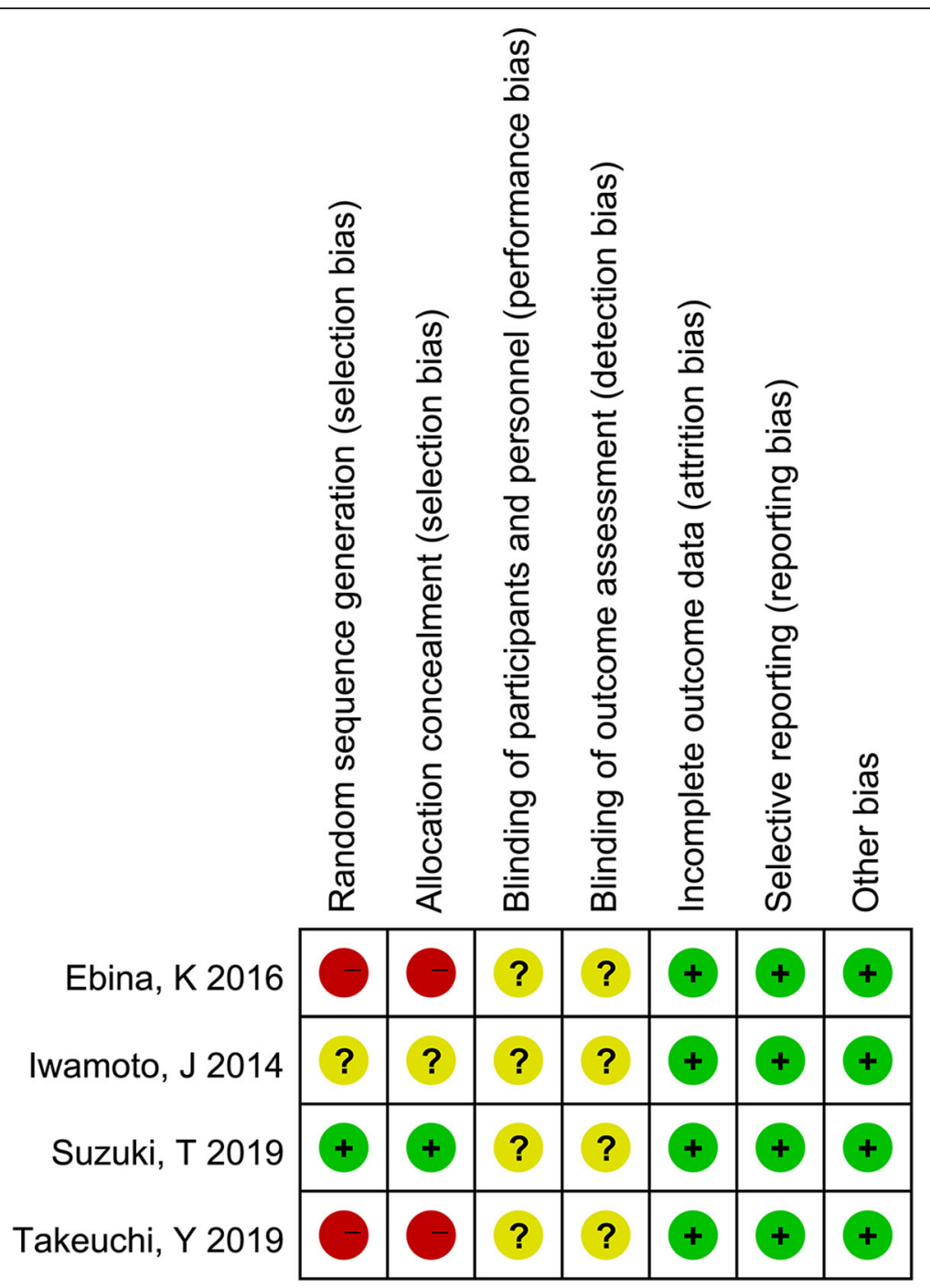

Fig. 3 Summary of the risk of bias for each included study. "+" (green): low risk of bias; "?" (yellow): unclear risk of bias; "--" (red): high risk of bias

and serum phosphorus with follow-up time less than 6 months. The results of meta-analysis for serum calcium $($ WMD $(95 \% \mathrm{CI})=0.0507(-0.0904,0.1919) \mathrm{mg} / \mathrm{dL}, P=$ 0.48 ; heterogeneity: $\left.I^{2}=33 \%, P=0.22\right)$ and serum phosphorus (WMD $(95 \% \mathrm{CI})=-0.1868(-0.4890,0.1153)$ $\mathrm{mg} / \mathrm{dL}$; heterogeneity: $\left.I^{2}=60 \%, P=0.23\right)$ showed that the difference of ELD + BP vs. BP was not significant in both serum calcium (Fig. 4d) and serum phosphorus (Fig. 4e). Additionally, a total of 3 studies [27-29] reported the outcomes of serum TRACP-5b with followup time less than 6 months. Since the heterogeneity test among these 3 studies [27-29] were statistically significant $\left(I^{2}=92 \%, P<0.00001\right)$, the random-effect model was used. The difference of serum TRACP-5b between ELD + BP and BP (WMD $(95 \% \mathrm{CI})=7.3022$ $(-104.4043,119.0087) \mathrm{mU} / \mathrm{dL}, P=0.90)$ (Fig. $4 \mathrm{f}$ ) was not significant.
Three studies [27-29] reported the results of LS-BMD (Fig. 5a) and serum TRACP-5b (Fig. 5b) with 12-month follow-up. The result showed that there was no significant heterogeneity $\left(I^{2}=0 \%, P=0.50\right)$ of LS-BMD between ELD $+\mathrm{BP}$ and BP; thus, the fixed-effect model analysis was performed $\left(\right.$ WMD $(95 \%$ CI $)=0.0231(0.0108,0.0355) \mathrm{g} / \mathrm{cm}^{2}, P$ $=0.0002)$. Meanwhile, there was a significant heterogeneity $\left(I^{2}=81 \%, P=0.005\right)$ of serum TRACP-5b between ELD + $\mathrm{BP}$ and $\mathrm{BP}$, and the combined result of the random-effects model was WMD $(95 \% \mathrm{CI})=7.3507(-71.9028,86.6042)$ $\mathrm{mU} / \mathrm{dL}, P=0.86$. Moreover, two studies $[28,29]$ reported the comparison of FN-BMD (Fig. 5c) and TH-BMD (Fig. $5 \mathrm{~d})$ with 12-month follow-up. The result of the metaanalysis for FN-BMD was WMD $(95 \% \mathrm{CI})=0.0114(-$ $0.0103,0.0331) \mathrm{g} / \mathrm{cm}^{2}, P=0.30$ (heterogeneity test result: $I^{2}$ $=77 \%, P=0.04)$. The result of TH-BMD was WMD $(95 \%$ CI $)=0.0078 \quad(-0.0167,0.0322) \mathrm{g} / \mathrm{cm}^{2}, \quad P=0.53$ 


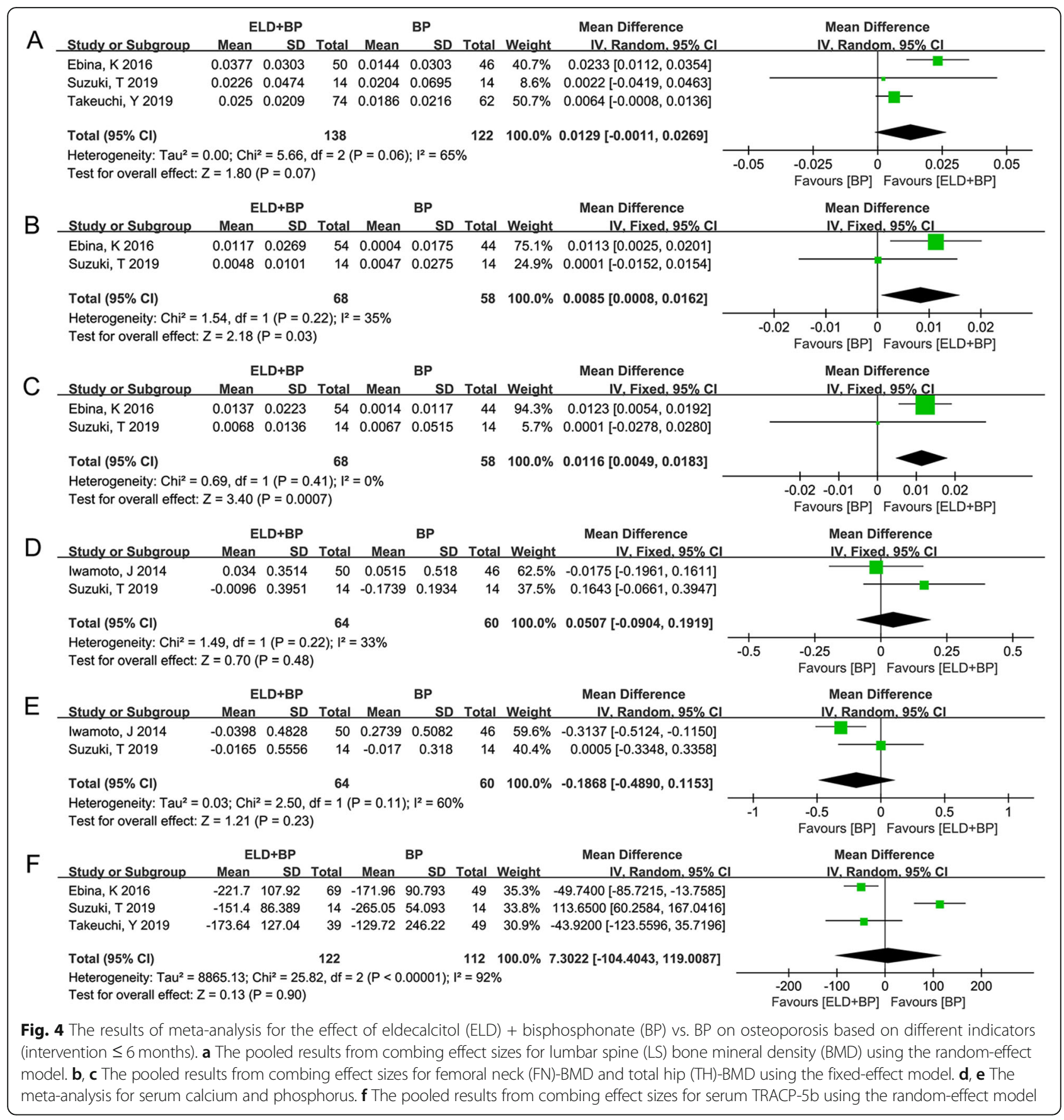

(heterogeneity test result: $I^{2}=78 \%, P=0.03$ ). However, the meta-analysis was not performed on the outcomes of serum calcium and serum phosphorus with 12-month follow-up due to the small sample size (only 1 study reported).

\section{Discussion}

The result of current meta-analysis showed that the effect of ELD + BP was superior to BP alone based on indicators including FN-BMD and TH-BMD in patients with followed up $\leq 6$ months. Meanwhile, the effect of $\mathrm{ELD}+\mathrm{BP}$ was superior to BP alone based on LS-BMD in patients with 12 months follow-up. However, there was no significant difference between ELD + BP and BP with other indicators such as serum calcium in patients with follow-up $\leq 6$ months or 12 months.

The prevalence of osteoporosis and low bone mass can be estimated by FN-BMD and TH-BMD in adults 50 years and older [31, 32]. The quality of postmenopausal osteoporosis patients is increased when receiving 


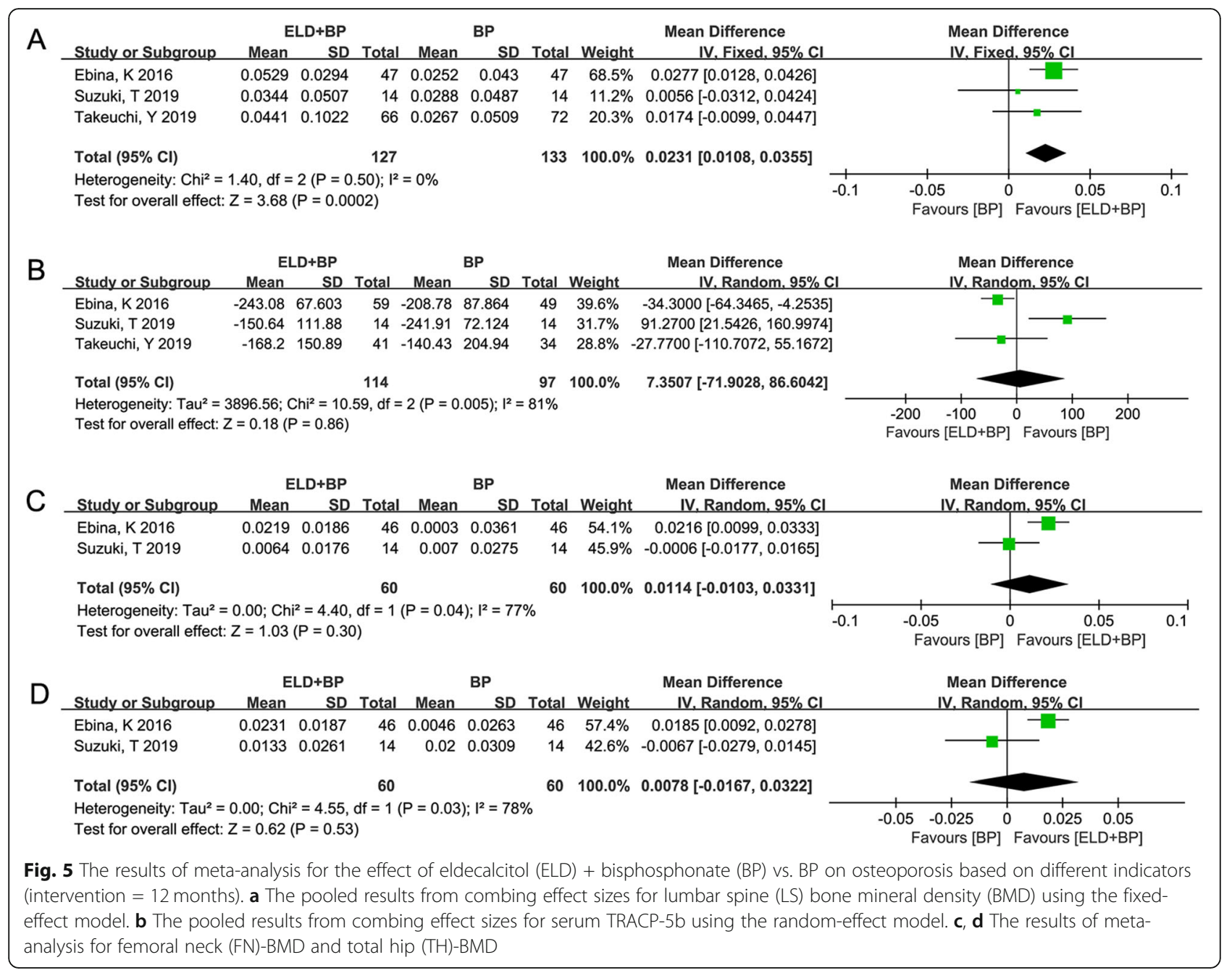

weekly BP treatment [9]. Based on a certain mechanism of cell regulation, BP can improve the bone density of patients and reduce the bone turnover, so as to reduce the possibility of fracture [33]. However, elderly, postmenopausal, osteoporotic obese women are resistant to long-term BP, especially in regions of the $\mathrm{TH}, \mathrm{FN}$, and forearm compared with the spine [34]. Although BP is indicated in the prevention and treatment during the process of osteoporosis, BMD continues to decline in up to $15 \%$ of BP users [35]. It is proved that with the increase of time, BP can effectively slow down the speed of bone gain [36]. As an active analog of vitamin D, ELD is commonly used in the treatment of osteoporosis [12]. ELD can reduce the re-absorption of blood calcium into the bone, improve the absorption of calcium in the intestine, and then increase the bone density in osteoporosis patients [13]. A previous study shows that ELD has a significant effect in additionally decreasing the level of the bone resorption, even in the osteoporosis patients who undergo the long-time therapy of BP [37]. Actually, ELD + BP has been proven to be effective for the treatment of osteoporotic patients in Japan [38]. Kamimura et al. indicated that ELD provided additive increasing in patients with long-term BP therapy based on the detection of indicators such as BMD and bone turnover [15]. In this meat-analysis, the result showed that the effect of ELD + BP was superior to BP alone based on indicators including FN-BMD and TH-BMD in patients with follow-up $\leq 6$ months. Meanwhile, the effect of ELD + BP was superior to BP alone based on LS-BMD in patients with 12 months follow-up. Thus, we speculated that the therapeutic effect of ELD + BP was superior to $\mathrm{BP}$ alone in osteoporotic patients based on the influence of BMD.

As we all know, the calcium balance or calcium homeostasis is very important to human bone health, which is achieved by the continuous transformation between osteoblasts and osteoclasts [39]. In postmenopausal women, ELD increases urinary calcium, consistent with an increase in intestinal absorption, and reduces markers of bone turnover [40]. Compared to alfacalcidol, ELD can effectively inhibit bone resorption by urinary serum calcium 
excretion, which further indicates a better osteoprotective effect of ELD in osteoporotic patients [41]. Furthermore, the effect of $\mathrm{BP}$ on bone resorption, calcium balance, and BMD has already been proven in vivo [42]. A previous study shows that BP can be used to regulate the serum calcium in hypercalcemia [43]. In the current metaanalysis, there was no significant difference between ELD $+\mathrm{BP}$ and BP with indicators such as serum calcium in patients with followed up $\leq 6$ months or 12 months. This result showed that the difference in the effects of ELD + $\mathrm{BP}$ and $\mathrm{BP}$ alone on blood calcium regulation was not significant, indicating a good reliability of ELD + BP in clinical use.

There were some limitations in the current study. First, the heterogeneity in this study is not ideal. The reason for heterogeneity might be the types of drugs included in BP which were not identical. Second, there was no publication bias test for the current study, since there were only four studies included (only from Japan), which is not suitable for publication bias test. Even so, this study might be the first meta-analysis on the efficacy of ELD + BP vs. BP in the treatment of osteoporosis. Meanwhile, there was no significant heterogeneity in the included literature, indicating that the results of metaanalysis were reliable.

\section{Conclusion}

In conclusion, the therapeutic effect of ELD + BP was superior to $\mathrm{BP}$ alone in osteoporotic patients based on the influence of BMD. However, further rigorous and high-quality validation studies based on a large sample size are needed in the future.

\section{Acknowledgements}

None.

\section{Authors' contributions}

Conception and design of the research: ZZ; acquisition of data: ZZ; analysis and interpretation of data: $J L_{;}$statistical analysis: JL; obtaining funding: ZZ; drafting the manuscript: ZZ; revision of manuscript for important intellectual content: ZZ. All authors read and approved the final manuscript.

\section{Funding}

This study was supported by the Zhejiang Public Technology and Policy Science (social science) Applied Research Project (No. 2020C35071) and Zhejiang Medical Science and Technology Project (No. 2020KY086).

\section{Availability of data and materials}

The data used to support the findings of this study are available from the corresponding author upon request.

\section{Ethics approval and consent to participate}

This article does not contain any studies with human participants or animals performed by any of the authors.

\section{Consent for publication}

Not applicable.

\section{Competing interests}

The authors declare that they have no conflict of interest.

\section{Author details}

'Department of Pharmacy, Tongde Hospital of Zhejiang Province, Hangzhou 310012, Zhejiang, China. ${ }^{2}$ Division of Medical Administration, Tongde Hospital of Zhejiang Province, Hangzhou 310012, Zhejiang, China.

${ }^{3}$ Department of Medicine, Zhejiang Academy of Traditional Chinese Medicine, Hangzhou 310012, Zhejiang, China. ${ }^{4}$ Hemopurification Center, Division of Nursing, Tongde Hospital of Zhejiang Province, No. 234 Gucui Road, Xihu District, Hangzhou 310012, Zhejiang Province, China.

Received: 22 April 2020 Accepted: 16 August 2020

Published online: 09 September 2020

\section{References}

1. Kanis JA. Diagnosis and clinical aspects of osteoporosis. Pocket Reference to Osteoporosis: Springer; 2019. p. 11-20.

2. Sànchez-Riera L, Carnahan E, Vos T, Veerman L, Norman R, Lim S, et al. The global burden attributable to low bone mineral density. Ann Rheum Dis. 2014;73(9):1635-45.

3. Bonnick SL, Shulman L. Monitoring osteoporosis therapy: bone mineral density, bone turnover markers, or both? Am J Med. 2006;119(4):S25-31.

4. Kaufman J-M, Orwoll E, Goemaere S, San Martin J, Hossain A, Dalsky G, et al. Teriparatide effects on vertebral fractures and bone mineral density in men with osteoporosis: treatment and discontinuation of therapy. Osteoporos Int. 2005;16(5):510-6.

5. Fink HA, MacDonald R, Forte ML, Rosebush CE, Ensrud KE, Schousboe JT, et al. Long-term drug therapy and drug discontinuations and holidays for osteoporosis fracture prevention: a systematic review. Ann Intern Med. 2019; 171(1):37-50.

6. Ensrud KE, Crandall CJ. Bisphosphonates for postmenopausal osteoporosis. JAMA. 2019:322(20):2017-8.

7. Naylor K, McCloskey E, Jacques R, Peel N, Paggiosi M, Gossiel F, et al. Clinical utility of bone turnover markers in monitoring the withdrawal of treatment with oral bisphosphonates in postmenopausal osteoporosis. Osteoporos Int. 2019;30(4):917-22

8. Kocijan R, Weigl M, Skalicky S, Geiger E, Ferguson J, Leinfellner G, et al. MicroRNA levels in bone and blood change during bisphosphonate and teriparatide therapy in an animal model of postmenopausal osteoporosis. Bone. 2020;131:115104.

9. Hagino H, Soen $\mathrm{S}$, Sugimoto T, Endo N, Okazaki R, Tanaka K, et al. Changes in quality of life in patients with postmenopausal osteoporosis receiving weekly bisphosphonate treatment: a 2-year multicenter study in Japan. J Bone Miner Metab. 2019;37(2):273-81.

10. Fiscaletti M, Loucos R, Jamil KA, Biggins A, Munns C, Pacey V, editors. Does prior bisphosphonate therapy in children and adolescents with cerebral palsy alter surgical outcomes? 9th International Conference on Children; 2019: BioScientifica.

11. Cummings SR, Lui L-Y, Eastell R, Allen IE. Association between drug treatments for patients with osteoporosis and overall mortality rates: a meta-analysis. JAMA Intern Med. 2019;179(11):1491-500.

12. Wang W, Gao Y, Liu H, Feng W, Li X, Guo J, et al. Eldecalcitol, an active vitamin $\mathrm{D}$ analog, effectively prevents cyclophosphamide-induced osteoporosis in rats. Experimental and Therapeutic Medicine. 2019;18(3): $1571-80$.

13. Jiang $Y$, Tang $H$, Ma $X$, Cheng $Q$, Lin $H$, Jin $X$, et al. Eldecalcitol increases bone mineral density in Chinese osteoporotic patients without vitamin $\mathrm{D}$ or calcium supplementation. J Bone Miner Metab. 2019;37(6):1036-47.

14. Matsumoto T, Yamamoto K, Takeuchi T, Tanaka Y, Tanaka S, Nakano T, et al. Eldecalcitol is superior to alfacalcidol in maintaining bone mineral density in glucocorticoid-induced osteoporosis patients (e-GLORIA). J Bone Min Metab. 2020:1-11.

15. Kamimura M, Ikegami S, Mukaiyama K, Koiwai H, Nakamura Y, Taguchi A, et al. Additive effects of eldecalcitol in poorly responding long-term bisphosphonate treatment for osteoporosis. Osteoporosis and Sarcopenia. 2019;5(2):57-61.

16. Kinoshita M, Ishijima M, Kaneko H, Liu L, Nagao M, Sadatsuki R, et al. The increase in bone mineral density by bisphosphonate with active vitamin $D$ analog is associated with the serum calcium level within the reference interval in postmenopausal osteoporosis. Mod Rheumatol. 2019;29(1):157-64.

17. Wang J, Li H. Treatment of glucocorticoid-induced osteoporosis with bisphosphonates alone, vitamin $D$ alone or a combination treatment in eastern Asians: a meta-analysis. Curr Pharm Des. 2019;25(14):1653-62. 
18. Ebina K, Hashimoto J, Kashii M, Hirao M, Kaneshiro S, Noguchi T, et al. The effects of switching daily teriparatide to oral bisphosphonates or denosumab in patients with primary osteoporosis. J Bone Miner Metab. 2017;35(1):91-8

19. Watts NB, Diab DL. Long-term use of bisphosphonates in osteoporosis. The Journal of Clinical Endocrinology \& Metabolism. 2010;95(4):1555-65.

20. Otto S, Abu-ld MH, Fedele S, Warnke PH, Becker ST, Kolk A, et al. Osteoporosis and bisphosphonates-related osteonecrosis of the jaw: not just a sporadic coincidence-a multi-Centre study. J Cranio-Maxillofac Surg. 2011:39(4):272-7.

21. Higgins JP, Green S. Cochrane handbook for systematic reviews of interventions: Wiley online library; 2008

22. Higgins JP, Thompson SG, Deeks JJ, Altman DG. Measuring inconsistency in meta-analyses. BMJ (Clinical research ed). 2003 Sep 6;327(7414):557-60. PubMed PMID: 12958120. PMCID: 192859. Epub 2003/09/06. eng.

23. Iwamoto J, Sato Y. Eldecalcitol improves chair-rising time in postmenopausal osteoporotic women treated with bisphosphonates. Therapeutics and clinical risk management. 2014;10:51-9. PubMed PMID: 24476669. PMCID: Pmc3897513. Epub 2014/01/31. eng.

24. Suzuki T, Nakamura $Y$, Kato $H$. Effects of monthly minodronate with or without eldecalcitol addition in osteoporosis patients with rheumatoid arthritis: an 18-month prospective study. Osteoporosis and sarcopenia. 2019 Dec;5(4):122-7. PubMed PMID: 31938731. PMCID: Pmc6953524. Epub 2020/ 01/16. eng.

25. Ebina K, Noguchi T, Hirao M, Kaneshiro S, Tsukamoto Y, Yoshikawa H. Comparison of the effects of 12 months of monthly minodronate monotherapy and monthly minodronate combination therapy with vitamin K2 or eldecalcitol in patients with primary osteoporosis. J Bone Miner Metab 2016 May;34(3):243-250. PubMed PMID: 26303222. Epub 2015/08/26. eng.

26. Takeuchi Y, Hashimoto J, Kakihata H, Nishida Y, Kumagai M, Yamagiwa C. Effectiveness of monthly intravenous ibandronate injections in a real-world setting: subgroup analysis of a postmarketing observational study. Osteoporosis and sarcopenia. 2019 Mar;5(1):11-8. PubMed PMID: 31008373. PMCID: Pmc6452926. Epub 2019/04/23. eng.

27. Takeuchi Y, Hashimoto J, Kakihata H, Nishida Y, Kumagai M, Yamagiwa C. Effectiveness of monthly intravenous ibandronate injections in a real-world setting: subgroup analysis of a postmarketing observational study. Osteoporosis and Sarcopenia. 2019;5(1):11-8.

28. Ebina K, Noguchi T, Hirao M, Kaneshiro S, Tsukamoto Y, Yoshikawa H. Comparison of the effects of 12 months of monthly minodronate monotherapy and monthly minodronate combination therapy with vitamin $\mathrm{K} 2$ or eldecalcitol in patients with primary osteoporosis. J Bone Miner Metab. 2016;34(3):243-50.

29. Suzuki T, Nakamura $Y$, Kato $H$. Effects of monthly minodronate with or without eldecalcitol addition in osteoporosis patients with rheumatoid arthritis: an 18-month prospective study. Osteoporosis and Sarcopenia. 2019:5(4):122-7.

30. Iwamoto J, Sato Y. Eldecalcitol improves chair-rising time in postmenopausal osteoporotic women treated with bisphosphonates. Ther Clin Risk Manag. 2014;10:51.

31. Wright NC, Looker AC, Saag KG, Curtis JR, Delzell ES, Randall S, et al. The recent prevalence of osteoporosis and low bone mass in the United States based on bone mineral density at the femoral neck or lumbar spine. J Bone Miner Res. 2014;29(11):2520-6.

32. Shin CS, Choi HJ, Kim MJ, Kim JT, Yu SH, Koo BK, et al. Prevalence and risk factors of osteoporosis in Korea: a community-based cohort study with lumbar spine and hip bone mineral density. Bone. 2010;47(2):378-87.

33. Bourrin S, Ammann P, Bonjour J, Rizzoli R. Recovery of proximal tibia bone mineral density and strength, but not cancellous bone architecture, after long-term bisphosphonate or selective estrogen receptor modulator therapy in aged rats. Bone. 2002;30(1):195-200

34. Dagdelen S, Sener D, Bayraktar M. Influence of type 2 diabetes mellitus on bone mineral density response to bisphosphonates in late postmenopausal osteoporosis. Adv Ther. 2007;24(6):1314-20.

35. Heckman GA, Papaioannou A, Sebaldt RJ, loannidis G, Petrie A, Goldsmith C, et al. Effect of vitamin D on bone mineral density of elderly patients with osteoporosis responding poorly to bisphosphonates. BMC Musculoskelet Disord. 2002;3(1):6.

36. Orr-Walker B, Wattie DJ, Evans MC, Reid IR. Effects of prolonged bisphosphonate therapy and its discontinuation on bone mineral density in post-menopausal osteoporosis. Clin Endocrinol. 1997;46(1):87-92.
37. Iba K, Sonoda T, Takada J, Dohke T, Yamashita T. Further significant effects of eldecalcitol on bone resorption markers and bone mineral density in postmenopausal osteoporosis patients having undergone long-term bisphosphonate treatment. J Bone Miner Metab. 2017;35(2):171-6.

38. Mukaiyama K, Uchiyama S, Nakamura Y, Ikegami S, Taguchi A, Kamimura M, et al. Eldecalcitol, in combination with bisphosphonate, is effective for treatment of Japanese osteoporotic patients. Tohoku J Exp Med. 2015; 237(4):339-43.

39. Cashman K. Calcium intake, calcium bioavailability and bone health. Br J Nutr. 2002;87(S2):S169-S77.

40. Sanford M, McCormack PL. Eldecalcitol. Drugs. 2011;71(13):1755-70.

41. Matsumoto T, Takano T, Yamakido S, Takahashi F, Tsuji N. Comparison of the effects of eldecalcitol and alfacalcidol on bone and calcium metabolism J Steroid Biochem Mol Biol. 2010;121(1-2):261-4.

42. Ammann P, Rizzoli R, Caverzasio J, Shigematsu T, Slosman D, Bonjour JP. Effects of the bisphosphonate tiludronate on bone resorption, calcium balance, and bone mineral density. J Bone Miner Res. 1993;8(12):1491-8.

43. van Breukelen FJ, Bijvoet OL, Frijlink WB, Sleeboom HP, Mulder H, van Oosterom AT. Efficacy of amino-hydroxypropylidene bisphosphonate in hypercalcemia: observations on regulation of serum calcium. Calcif Tissue Int. 1982;34(1):321-7.

\section{Publisher's Note}

Springer Nature remains neutral with regard to jurisdictional claims in published maps and institutional affiliations.
Ready to submit your research? Choose BMC and benefit from:

- fast, convenient online submission

- thorough peer review by experienced researchers in your field

- rapid publication on acceptance

- support for research data, including large and complex data types

- gold Open Access which fosters wider collaboration and increased citations

- maximum visibility for your research: over $100 \mathrm{M}$ website views per year

At BMC, research is always in progress.

Learn more biomedcentral.com/submissions 